\title{
Difficulties in teaching the concepts of 'amount of substance' and 'mole'
}

Carlos Furio, Department of Didactics of Experimental and Social Sciences, University of Valencia, Rafael Azcona, 'Talaia-Hondarribia' High-School, Fenaro Guisasola, Department of Applied Physics I, University of the Basque Country, Spain and Mary Ratcliffe, Research and Graduate School of Education, University of Southampton, UK

In this study the origin and evolution of the meanings of the concepts 'amount of substance' and 'mole' are described. Serious disagreements about these concepts amongst chemistry teachers and the recommendations of the international scientific community are identified. Attention is also drawn to the didactic implications that these epistemological difficulties may have for the teaching of chemistry.

\section{Introduction}

There has been a growing concern over recent decades with the teaching and learning of the concept of 'mole' (Dierks 1881, Lazonby et al. 1982, Nelson 1991, Staver and Lumpe 1993, Tullberg et al. 1994). It is an important issue, not only because of the repercussions it may have on the teaching and learning of this concept, but also because of its consequences for the solving of stoichiometry problems (Dori and Hameiri 1998, Schmidt 1990). The 'mole' is the unit of one of the seven fundamental physical quantities (the 'amount of substance'). However, as IUPAC (Mills et al. 1993) and other researches have pointed out (Furió et al. 1993, Stromdahl 1994, Azcona 1997), teachers do not have a good understanding of it.

This study looks into the reasons why the concept of mole is poorly understood by students, the hypothesis posed being that this has to do with some teachers' lack of knowledge about the origin and evolution of the meaning of the concepts 'amount of substance' and 'mole'. Three main questions are addressed:

- What ideas do chemistry teachers in high schools have about the concepts of 'amount of substance' and its unit, the 'mole'?

- To what extent do teachers' ideas about these concepts agree with the meaning currently attached to them by the international chemistry community through IUPAC?

- Is there any relationship between the difficulty in understanding these concepts by teachers and their lack of awareness of the problems which arose in the historic construction of them? 
This paper begins by analysing the origins and historical development of the concepts 'amount of substance' and 'mole', until their current meanings are reached within the concepts of the atomic-molecular theory of matter. With this epistemological referent the meanings attributed to these concepts by chemistry teachers and to what extent they differ from those accepted by the scientific community are studied.

\section{Origin and evolution of the concepts 'amount of substance' and 'mole'}

Understanding a scientific concept involves knowing more than its precise definition (Furió and Guisasola 1998). It is necessary to know in what contexts it arises, what other concepts it is related to and differentiated from, in what social-historical conditions it was constructed and what changes it has undergone. Epistemologists agree that theories and concepts undergo historical changes that can sometimes be gradual (Toulmin 1972) and sometimes more radical. In the latter case, it is considered impossible to compare the new concept with the old one (Kuhn 1962).

Changes to a concept can be analysed through studying the context of the research within which it was constructed and through examining the extent of change of this theoretical frame over time. This is what has been done in the case of the quantity 'amount of substance' and its unit, the 'mole'. To start with, it is advisable to point out an anomaly in the development of these concepts: the unit 'mole' defined by Ostwald in 1900 came before the introduction by the scientific community of the quantity 'amount of substance' in 1961. Therefore, we shall go back to the 19 th century in order to recall into what theories and socialhistorical conditions these concepts were introduced, and to examine any change in the theoretical frame during the 20th century.

\section{Historical origin of the concept of 'mole'}

Ostwald (1900) introduced the concept of 'mole' due to his scepticism with regard to the atomic hypothesis, although he accepted it later in 1908 (Thuillier 1990). This sceptical attitude is reflected in his original work Grundlinien der Anorganischen Chemie:

To the extent indicated here, the atomic hypothesis has turned out to be a very effective resource for learning and research, since it makes the conception and use of general laws much easier. However, one must not be seduced by this correspondence between image and reality to the point of confusing them (...). From the extent to which relations of chemical processes have been treated thus far, $i t$ would appear that substances are made up, in the sense indicated, of atoms. From this we have, at best, the possibility, but not the certainty, that they actually are. It cannot be demonstrated that the laws of chemical union could not be inferred from a completely different assumption. There is no need to give up the use of the atomic hypothesis, if we keep in mind that it is an illustration of the actual relations under an easy to handle functional image, but in no case may it be subtitled for the authentic relations. We must always be ready for reality to behave, sooner or later, in a different way from what we would expect from this image (Ostwald 1900:155, authors' translation).

The terminology used by Ostwald confirms what was said about the molecular hypothesis: 
The molecular hypothesis agrees with the concept of normal weight presented formerly (p. 92 and 148) in Gay-Lussac's law in the same relationship as the atomic hypothesis with the concept of weight of union, and normal weight shown, in the light of the hypothesis, as the relative weight of a molecule or as the molecular weight.

The name molecular weight is generally used for the concept of normal weight. It can also be used independently from the hypothesis it is based on, if we have in mind that it expresses a real proportion, that is, the density of the gases.

The same developed hypothesis was established at almost the same time in 1811 by Avogadro and in 1812 by Ampere. The assumption that in equal volumes of gas there would be equal number of molecules is usually known as Avogadro's law. This is deceiving, since a hypothesis can never be a law. It can be called Avogadro's postulate. The law which serves as a basis for these considerations is that of the relations of volume in reactions among gases, discovered by Gay-Lussac. (Ostwald 1900: 156157 , authors' translation)

When introducing the 'mole' concept in 1900, Ostwald was seeking the chemical formula for 'oxygenated water', and he wanted to determine the 'normal weight' of this substance through the proportionality between the decrease of the freezing point and the concentration of a solution of such a compound. Here, Ostwald repeatedly uses the term 'amount of substance' identified as mass, and then he defines the 'mole' as follows:

Thus we have observed that if we dilute one 'mole' (the normal or molecular weight of a substance expressed in grams shall be called 'mole' from now on) of any substance in 1 litre or $1000 \mathrm{~g}$ of water, the resulting solution will freeze at $-1.850^{\circ}$. (Ostwald 1900 : 163 , authors' translation).

One of the main problems chemistry faced when becoming a science in the late 18 th century was to fix both the composition of compounds by mass and the quantitative proportions by mass of substances combining in chemical reactions. An expression of the paradigm of equivalents of chemistry in the 19th century is the law of proportions defined by Proust in 1799: elements combining to form a compound do so in a specific relation to their respective masses. So, the equivalent masses of the elements and those of the compound can be calculated as the sum of the equivalent masses of the elements that take part in the composition. Thus, atomistic-like interpretations would be unnecessary to solve problems related to stoichiometry and it was possible to rank chemistry's mathematical rigor equally with physics.

At the beginning of the 20th century the atomic hypothesis was still being questioned by Ostwald, himself, at the Faraday Conference held on 19 April 1904. These are what he said were the most important achievements of chemistry in his time:

(... ) It is possible to deduce all the stoichiometric laws (law of constant proportions, law of multiple proportions and law of weights of combination) from the principles of chemical dynamic, which makes it unnecessary to this purpose the atomic hypothesis, so setting the theory of stoichiometric laws on a basis more secure than that provided by a simple hypothesis. (Knight, 1968: 508-509).

Ostwald uses Richter's 'equivalentist philosophy'. He clearly shows his serious doubts about Dalton's atomic hypothesis and about Avogadro's molecular hypothesis. He casts doubt on the idea of the molecule and that of the gram-molecule used by his contemporary atomistics, but feeling reluctant to use molecular weight he uses Richterian terminology instead (normal weight instead of molecular weight, 
union weight instead of atomic weight). Ostwald's reluctance to use the idea of molecular weight kept on appearing even after he had accepted the existence of atoms:

(...) The atomic weight of hydrochloric [*] is $1,01+35,36=36,47$ for all the reactions that can be made with it. (Ostwald 1930:232).

"Pupil: Every element has an atomic weight and the atomic weight of the compound [*] is the addition of the atomic weights of their elements.

Teacher: Right. (Ostwald 1930: 234). [*] Translated and underlined by the authors of the article)

Rejecting the atomic-molecular hypothesis, Ostwald (1900) introduces and defines the 'mole' concept, as the normal or molecular weight expressed in grams, identifying it with a mass quantity. This is consistent with the equivalentist paradigm, but it is inconsistent with the interpretation of the chemical reactions based on the hypothesis of Dalton and Avogadro. Nelson (1991) points out that the terminology used by Ostwald favoured his purpose, since the word 'mole' in Latin means 'big mass' ('mole'), as opposed to molecule (small mass), so the 'mole' was a mass.

In the English (Ostwald 1902), French (Ostwald 1904) and Spanish versions (Ostwald 1917) of Ostwald (1900), the translators (A. Findley for the English version, L. Lazard for the French one and A. García for the Spanish one) 'correct' the author when using 'molar weight' instead of 'normal weight'. This 'terminology alteration' is kept throughout the text. In the English translation, on defining the 'mole', we read:

Thus it has been established that when one gram-molecule or one 'mole' (the molar or molecular weight of a substance expressed in grams) of any substance is dissolved in a litre or $1000 \mathrm{gm}$ of water, the solution produced freezes at $-1.850^{\circ}(\ldots)$. (Ostwald 1902: 156)

In the French translation:

It has been established that when dissolved in 1 litre, or $1.000 \mathrm{~g}$ of water, 1 'mole' of any matter (called gram-molecule or 'mole' for short, as we will call the molar weight expressed in grams from now on), the solution thus formed freezes at $-1.850^{\circ}(\ldots)$. (Ostwald 1904: 186, authors' translation)

And in the Spanish translation:

Thus it has been seen that, when dissolving in one litre or $1.000 \mathrm{gr}$ of water one 'mole' of any substance (from now on we shall call the molar weight of any matter, expressed in grams, a 'mole'), the solution produced freezes at $-1.86^{\circ}$ (... Ostwald 1917: 192, authors' translation).

The comparison of these versions with the original illustrates that Ostwald's persistence in using Richter's language (normal weight instead of molar weight) is not fully accepted by his contemporaries in the early 20th century. In the translated versions of the original text the terms 'normal weight' and 'weight of union' are not used any longer. In the original work and in other versions the 'mole' with 'molar weight' are identified with 'molecular weight expressed in grams'.

\section{Introduction of the quantity 'amount of substance'}

It has been shown that Ostwald identified 'amount of substance' with weight (mass) within the equivalentist paradigm he adopted. But the solution given by 
the atomic-molecular theory to the problem of the quantitative relations in chemical reactions is based on the meaning of what a reaction is, symbolized in an equation that contains the chemical formulae of the atom and molecules of the substances that interact. According to this, there are some proportions of combination between the particles of the reagents and the products of reaction, indicated by the coefficients that precede the chemical formulae. By knowing the masses of the particles involved in a reaction it is possible to deduce the weight and volumetric relations of the combination. The translation to mass (expressed in grammes) of these quantities led to the introduction of the concepts of grammeatom, gramme-molecule, gramme-equivalent and the gramme-formula-mass. The idea was to make the 'paradigm of equivalents' and atomistic visions of chemical reactions converge. The relation between the atomic and equivalent weight was defined as 'valency' or the capacity of an element to combine.

It was not until the introduction of the quantity 'amount of substance' that the problem of the quantitative relations would be completely explained by the atomic-molecular theory. The atomistic point of view was more concerned with establishing the relation between amounts of particles involved in this reaction. All the same, from this sub-microscopic relation of elementary entities that combine we can get, on the macroscopic level, the relation of masses or volumes of combination of the reacting substances. The introduction of the quantity 'amount of substance' would make it easier to count elementary units. As it is impossible to count the particles directly this must be done in an indirect way: establishing comparisons of masses or volumes.

According to Guggenheim (1986) in the text Thermodynamics. An Advanced Treatment for Chemists and Physicists, it was in 1961 when the 'amount of substance' acquired the rank of fundamental quantity:

In 1961 the International Union of Pure and Applied Physics made the following recommendations: 'In the field of chemical and molecular physics, in addition to the basic quantities defined above having been defined by the Conférence Générale des Poids et Mesures, amount of substance is also treated as a basic quantity. The recommended basic unit is the mole, symbol: mol. The 'mole' is defined as the amount of substance, which contains the same number of molecules (or ions, or atoms, or electrons, as the case may be), as there are atoms in exactly 12 grams of the pure carbon nuclide ${ }^{12}$ C. (Guggenheim 1986: 2)

Following the IUPAC (The International Union of Pure and Applied Chemistry) adopted in 1965, an almost identical recommendation:

A mole is an amount of substance of specified chemical formula, containing the same number of formula units (atoms, molecules, ions, electrons, quanta, or other entities) as there are in 12 grams (exactly) of the pure nuclide ${ }^{12} \mathrm{C}$. (Guggenheim 1986: 3)

This accepts the recommendation that 'amount of substance' is a different quantity to mass. According to Dierks (1981), the definitions of 'mole' have evolved and now refer to the quantity 'amount of substance' of which it is the unit. Thus, the definition of 1971, the 14th Conférence Génerale des Poids et Mesures (CGPM) establishes more precisely the fundamental entities:

The mole is the amount of substance of a system which contains as many elementary entities as there are atoms in 0.012 kilogram of carbon- 12 . When the mole is used, the elementary entities must be specified and may be atoms, molecules, ions, electrons, other particles, or specified groups of such particles (14th CGPM, 1971). (Mills et al. 1993: 70) 
Currently, the IUPAC (Mills et al. 1993) recommends calling 'amount of substance' or 'chemical quantity', a quantity which has been long used without a proper name, simply as 'number of moles'. This 'amount of substance' is one of the seven fundamental physical quantities, clearly different from mass, volume and number of particles.

To sum up:

(1) The 'mole' concept was introduced by Ostwald, at the beginning of the 20 th century, with a meaning of weight (mass), in a context of scepticism towards Dalton's atomic hypothesis.

(2) Historically, the 'mole' concept was introduced before the quantity 'amount of substance' for which it is the unit. This, together with the evolution undergone by its meaning, accounts for the controversy in these concepts.

It is not surprising that the quantity 'amount of substance' was also given a meaning of mass, as is shown in the analysis of texts on chemistry. However, nowadays the scientific community, through the IUPAC, attaches a different meaning to it: it is the unit of the quantity that serves to count particles.

\section{Current meanings and definitions of 'amount of substance' and of mole}

Talking about the meaning currently assumed by the scientific community on the subject of 'amount of substance', as expressed through the publication of the IUPAC, Guggenheim (1961) said that:

We have all been taught at an early stage that mass and weight are different quantities although at a given place their ratio is constant. During the past score of years the view has been as accepted by a rapidly increasing number of physicists and chemists that there is a third quantity from mass and weight but proportional to both. This quantity was first named 'Stoffmenge' in German and the English translation is 'amount of substance'.

The amount of substance (symbolised $n$ ) is also called chemical amount in the publication of the IUPAC Quantities, Units and Symbols in Physical Chemistry (Mills et al. 1993):

The SI unit of amount of substance is the mole. The physical quantity 'amount of substance' should no longer be called 'number of moles', just as the physical quantity 'mass' should not be called 'number of kilograms'. The name 'amount of substance' and 'chemical amount' may often be usefully abbreviated to the single word 'amount', particularly in such phrases as 'amount concentration' and 'amount of $\mathrm{N}_{2}$ '.

With regard to the use of the word molar, it is said in that same publication that:

The adjective molar before the name of an extensive quantity generally means divided by amount of substance. (Mills et al. 1993: 7)

Therefore the units S.I. kg. mole ${ }^{-1}$ and $\mathrm{m}^{3} \cdot \mathrm{mole}^{-1}$ correspond to the molar mass, symbolized $M$ by IUPAC, and to the molar volume $\left(\mathrm{V}_{\mathrm{m}}\right)$ respectively. The IUPAC supports that the quantity expressing the proportion between the 'amount of substance' of the solute and the volume of a solution be called concentration or 'amount of substance' concentration, even though it admits that it is still also called molarity. 
Finally in the section devoted to the amount of substance and the specification of entities they express the need to point out clearly the type of elementary entities:

The amount of substance is proportional to the number of specified elementary entities of that substance; the proportionality factor is the same for all substances and is the reciprocal of the Avogadro constant. The elementary entities may be chosen as convenient, not necessarily as physically real individual particles. Since the amount of substance and all physical quantities derived from it depend on this choice it is essential to specify the entities to avoid ambiguities. (Mills et al. 1993: 46)

Following these recommendations we infer the need to distinguish clearly between 'amount of substance' $(n)$, mass $(m)$, volume $(V)$ and number of elementary entities $(N)$. In Figure 1 the corresponding operative expressions that relate $m, V$ and $N$ (where $M$ is the molar mass, $V_{m}$ the molar volume and $N_{A}$ the Avogadro constant) have been indicated. The quantity 'amount of substance' is defined in relation to mass, to volume or to the number of elementary entities contained in a particular substance, but it cannot be identified with any of those terms, that is: $n \neq m, n \neq V$ and $n \neq N$.

Following the different categories used by Doménech et al. (1993) in the definitions of the concept of mass, we can establish a parallelism for the 'amount of substance' and 'mole' concepts, which are the object of this study. Ostwald's initial definition (1900), in which he identifies 'mole' with normal or molecular weight of a substance expressed in grammes, could be regarded as an ontological definition rooted in Richterian equivalentism where 'amount of substance' is identified with mass. Modern expressions of the quantity 'amount of substance', refer to new definitions of a functional and relational type.

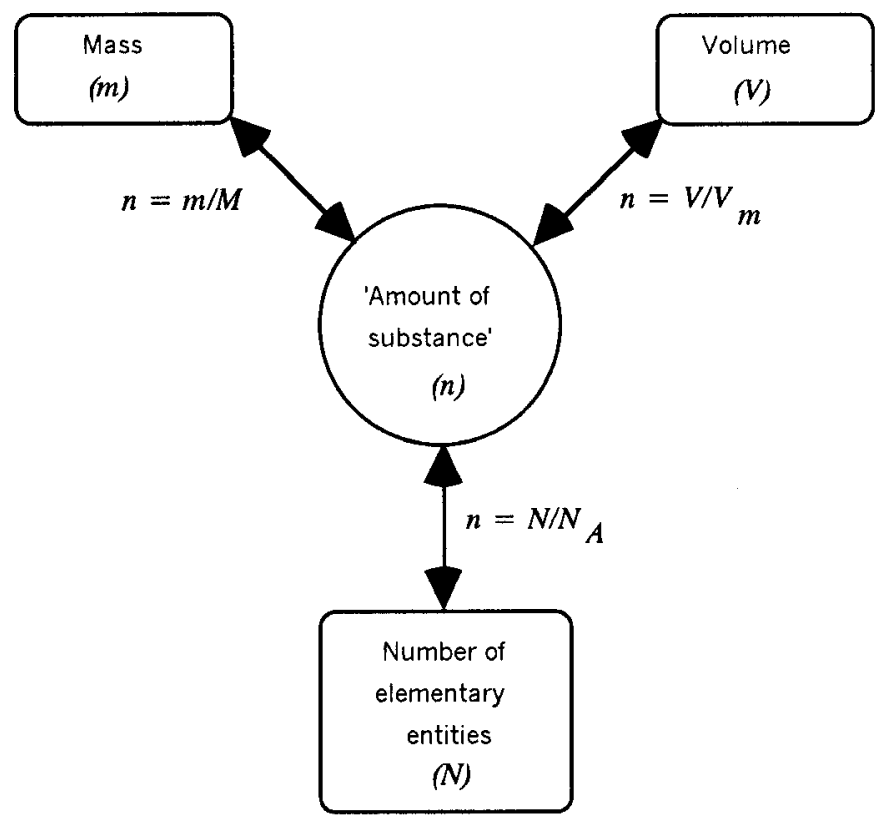

Figure 1. The 'amount of substance' in relation to other quantities. 
In fact, when referring to the quantity 'amount of substance' as that serving to count (in a macroscopic way) elementary entities, we are indicating what it is used for. The operative definitions are expressed through the relations to mass, to volume or to the number of elementary entities:

$$
n=m / M ; \quad n=V / M_{m} ; \quad n=N / N_{A}
$$

where the connections of ' $n$ ' with ' $m$ ', ' $V$ ' or ' $N$ ' are established, and would correspond to relational-like definitions. In this case it is not possible to establish an operational-like definition (through an instrument for the direct measure of 'amounts of substance'), although it is possible to measure it in an indirect way with a balance or counting particles (e.g. with a 'trap' or helions).

Currently, the scientific community, through the publications of the IUPAC, considers it anachronistic to use the concepts 'equivalent' and 'normality' as a way to express the concentration of solution, as can be seen from the lack of references to them in their recent publications. This shows that concepts may arise in a particular historical or theoretical context, evolve and, finally, may 'disappear'. This is the case with the concept of equivalent weight, which in an atomistic theoretical context is no longer necessary to solve the problem of the determination of proportions of mass in which substances combine in chemical reactions, and which has been replaced with the concepts 'amount of substance' and 'mole'. This is a consequence of full acceptance by the scientific community of the atomicmolecular theory in interpreting chemical reactions, that is, it is coherent with the change in the theoretical frame.

Having considered the origin and historical evolution of the concepts 'amount of substance' and 'mole', the paper now turns to teachers' views, based on the initial assumption that some teachers have insufficient knowledge of the evolution of these concepts.

\section{What ideas do teachers have about the 'amount of substance' and 'mole' concepts?}

In order to examine teachers' ideas about these concepts, we looked for epistemological deficiencies that might condition teaching practice. During their university training, teachers are not generally taught about the history of chemistry, and are therefore unaware of the origin and evolution of these concepts. In a previous study Furió et al. (1993) it was found that the operative introduction of the 'mole' concept deprives it of a chemical meaning and makes 'mole' difficult to understand by pupils with no previous ideas about this concept. This operational form of teaching may result from a non-problematic vision of science which gives students a decontextualized meaning of mole with Ostwald's definition as the only reference. A starting hypothesis will be that teachers have serious difficulties with the current meanings of 'amount of substance' and of 'mole'.

In the practise of teaching, the number of moles is either used instead of the quantity 'amount of substance' or is associated with the generic expression 'amount of matter' mainly accepted as mass. This paper's hypothesis involves assuming that the 'amount of substance' quantity is practically unknown to most teachers.

In accordance with the above, it is supposed that teachers have the notion that the 'mole' unit is introduced as a unit of 'chemical mass' that serves to count the 
elementary entities of different substances. If teachers do not have a clear idea that the 'mole' is the unit of 'amount of substance', the 'number of moles' will be identified with an amount of elementary entities. That is, the relationship between 'amount of substance' and number of elementary entities will be wrongly transformed into an identity. Therefore, we expect to find that most teachers wrongly identify the 'mole' with a 'chemical mass' and/or with an 'Avogadro number' of elementary entities.

\section{Experimental studies and samples used}

In order to examine the validity of the hypothesis posed eight experimental studies were used, including analysis of textbooks, surveys and interviews with samples of teachers.

Studies 1, 2 and 3 (part A) looked into teachers' ideas about the quantity 'amount of substance'. Some initial ideas resulted from surveying a group of teachers during their training (study 1). It was observed with which attribute (mass, volume or number of elementary entities) they associated the meaning of 'amount of substance'. For this a questionnaire with three items was designed within which they were asked to compare the 'amounts of substance' of several elementary substances. In each item, two substances were on the pans of a scale and it was possible to compare their masses, their respective volumes, and the number of atoms. There could be three coherent answers: those related the 'amount of substance' to the mass, or to the volume (associations of a nonatomistic type), or those related to the number of elementary entities (atomistic association). After this first approach it was analysed in depth as to whether this concept is taught or not (studies 2 and 3 ).

Textbooks are the curricular material most commonly used for the teaching of sciences at every educational level. This is why study 2 analysed how the concept 'amount of substance' is introduced by them. In addition, in order to delve deeper into the ideas about 'amount of substance' expressed by teachers in study 1, study 3, a structured interview was devised (De Jong 1994 and 1996).

In studies 4 and 5 (part B) any epistemological and didactic deficiencies in the usual teaching of the 'mole' concept was looked for. In study 4 the analysis of textbooks was used to check for the existence of references that account for the need to introduce the 'mole' concept (in relation to 'counting elementary entities') or for historical comments on the origin and development of this concept. Study 5 was a survey and an interview with teachers where they were asked what they consider a good method of introducing the 'mole' concept, considering its origin and development as well as the theoretical frame in which it is introduced.

If no context is provided when teaching these concepts, it is likely to find some confusion about them amongst teachers. Therefore, in a third step, another three studies (6, 7 and 8, part C) were devised to look into the existence of misconceptions in the usual teaching of them. In the first of these three studies it was analysed as to whether there are misconceptions in the introduction of the 'mole' concept in textbooks. Studies 7 and 8 looked at teachers' ideas of this concept through a questionnaire (study 7) and a structured interview (study 8). These studies are summarized in table 1. 
Table 1. Overview of the studies used

\begin{tabular}{|c|c|c|c|c|}
\hline Part & Study & Aim & Tools & Subject \\
\hline \multirow[t]{3}{*}{ A } & 1 & $\begin{array}{l}\text { To determine to what extent } \\
\text { the teacher trainees associate } \\
\text { ' } n \text { ' and ' } m \text { ' or ' } V \text { ' of a } \\
\text { substance }\end{array}$ & Questionnaire & $\begin{array}{l}\text { Concept of 'amount } \\
\text { of substance' }\end{array}$ \\
\hline & 2 & $\begin{array}{l}\text { To examine to what extent } \\
\text { ' } n \text { ' is not introduced but the } \\
\text { 'mole' is, and the 'number } \\
\text { of moles' is calculated. }\end{array}$ & $\begin{array}{l}\text { Protocol for the } \\
\text { analysis of texts. }\end{array}$ & $\begin{array}{l}\text { Concept of 'amount } \\
\text { of substance'. }\end{array}$ \\
\hline & 3 & $\begin{array}{l}\text { To determine what meaning } \\
\text { is attributed to the quantity } \\
\text { ' } n \text { ' by actual teachers. }\end{array}$ & $\begin{array}{l}\text { Structured } \\
\text { interview. }\end{array}$ & $\begin{array}{l}\text { Concept of 'amount } \\
\text { of substance'. }\end{array}$ \\
\hline \multirow[t]{2}{*}{ B } & 4 & $\begin{array}{l}\text { To show whether the 'mole' } \\
\text { concept, is introduced } \\
\text { non-problematically and } \\
\text { non-historically in textbooks. }\end{array}$ & $\begin{array}{l}\text { Protocol for the } \\
\text { analysis of texts. }\end{array}$ & 'Mole' concept. \\
\hline & 5 & $\begin{array}{l}\text { To show whether } \\
\text { actual teachers have a } \\
\text { non-problematic and } \\
\text { non-historical view of the } \\
\text { 'mole' concept. }\end{array}$ & $\begin{array}{l}\text { Questionnaire } \\
\text { and interview }\end{array}$ & 'Mole' concept. \\
\hline \multirow[t]{3}{*}{$\mathrm{C}$} & 6 & $\begin{array}{l}\text { To determine whether in } \\
\text { textbooks 'mole' is mistaken } \\
\text { with molar mass and/or } \\
\text { Avogadro number. }\end{array}$ & $\begin{array}{l}\text { Protocol for the } \\
\text { analysis of } \\
\text { textbooks. }\end{array}$ & 'Mole' concept. \\
\hline & 7 & $\begin{array}{l}\text { To examine whether the } \\
\text { actual teachers mistake 'n' } \\
\text { with ' } m \text { ' or with ' } N \text { '. }\end{array}$ & Questionnaire & $\begin{array}{l}\text { 'Amount of } \\
\text { substance' and } \\
\text { 'mole' concepts. }\end{array}$ \\
\hline & 8 & $\begin{array}{l}\text { To show the 'mole' } \\
\text { concept teachers have. }\end{array}$ & $\begin{array}{l}\text { Structured } \\
\text { interview. }\end{array}$ & 'Mole' concept. \\
\hline
\end{tabular}

\section{Description of the samples used}

All the teachers had a Bachelor Degree in Chemical Sciences. The first study began with a sample of secondary education trainee teachers $(n=36)$ because it was thought that these teachers would show the conceptions acquired during their university training more clearly. A sample of teachers in secondary education $(n=47)$ and university professors $(n=6)$, all of them currently teaching were then used.

The sample of textbooks used in studies 2 and 4 was made up by 87 books out of which 62 corresponded to secondary education (ages 16-17) and 25 to General Chemistry in secondary (18 year olds) and first year at university, all of them were published in the period 1976-1996. These books are considered of general use for the teaching of chemistry in secondary education and university. Many of the books were suggested by the teachers themselves and some others are prestigious international books used at university level.

In all the studies three external researchers validated the difficulty of the questions, the targets aimed at with each item and the analysis of results. 
Table 2. Trainee teachers having a confused idea on the quantity 'amount of substance' $(n=36)$

\begin{tabular}{lc}
\hline Meaning attributed to ' $n$ ' & Percentage \\
\hline As number of atoms & 44.4 \\
As mass & 38.9 \\
As volume & 5.5 \\
No answer & 5.5 \\
Incoherent answer & 5.5 \\
\hline
\end{tabular}

\section{Presentation and analysis of results}

The results obtained are presented in three sub-sections. First, the results corresponding to the first three studies concerning the teachers' ideas about the quantity 'amount of substance' are shown. In the second section, the results dealing with the non-problematic and non-historical introduction of the 'mole' concept (studies 4 and 5) are presented. In the third section, results dealing with teachers' conceptual mistakes concerning the 'mole' and 'amount of substance' concepts (studies 6,7 and 8) are offered.

The quantity 'amount of substance' has an uncertain existence in the teaching of chemistry

Table 2 shows the results obtained on applying the questionnaire to the sample of the first study. This table shows that under $50 \%$ of training teachers associate the quantity 'amount of substance' with an atomistic qualitative idea. In fact, the quantity ' $n$ ' is introduced to count elementary entities so (' $N$ '), ' $n$ ' and ' $N$ ' are related but not identical.

Table 3 shows the results obtained in study 2 (analysis of textbooks). These results clearly show how the quantity 'amount of substance' was neglected in

Table 3. Fundamental quantity 'amount of substance' not considered as an object of teaching in chemistry textbooks

\begin{tabular}{|c|c|c|c|c|}
\hline \multirow[b]{2}{*}{ Item } & \multirow[b]{2}{*}{ Propositional content } & \multicolumn{3}{|c|}{ Percentage } \\
\hline & & $\begin{array}{c}1976-1985 \\
(N=41)\end{array}$ & $\begin{array}{c}1986-1996 \\
(N=46)\end{array}$ & $\begin{array}{l}1976-1996 \\
\text { Total } \\
(N=87)\end{array}$ \\
\hline 1 & $\begin{array}{l}\text { The quantity 'amount of substance is } \\
\text { not introduced in an explicit way in } \\
\text { the textbook, there are no questions } \\
\text { or exercises or activities are posed on } \\
\text { this concept. }\end{array}$ & 100.0 & 91.3 & 95.4 \\
\hline 2 & $\begin{array}{l}\text { The textbooks pose questions, } \\
\text { exercises or activities where you are } \\
\text { asked to calculate the 'number of } \\
\text { moles'. }\end{array}$ & 68.3 & 97.8 & 83.9 \\
\hline 3 & $\begin{array}{l}\text { The 'number of moles' is not } \\
\text { explicitly identified with the 'amount } \\
\text { of substance'. }\end{array}$ & 100.0 & 73.9 & 86.2 \\
\hline
\end{tabular}


chemistry textbooks used during the decade 1976-1985, whereas during the years 1986-1996 we can see a positive but slight evolution towards explaining it. Taking the last 21 years together, it could be said that chemistry textbooks ignore the quantity 'amount of substance'. It is not considered as a direct question in the textbooks, or as an object for evaluation or test at the end of the unit or chapter. In item 2 it can be seen that textbooks mostly make some sort of reference to the calculation of the so-called 'number of moles' (an inappropriate expression), but as seen in item 3, this does not mean that the 'number of moles' is identified with the quantity 'amount of substance' (this only happens in $13.8 \%$ of the textbooks in the last 21 years).

As for the results obtained in the third study (structured interview directed to teachers), some literal examples of the answers obtained when asked about the meaning of the quantity 'amount of substance' are offered.

Question. In Science it is normal for every quantity to have its unit defined through universal agreement and acceptation. In this case, we know the 'mole' is a unit of the quantity 'amount of substance'. Which do you think is the meaning of this quantity?

[Example 1 (Itziar, teaching at university)]

01 Interviewer: In the official definition of the IUPAC the 'mole' is said to be the

04 Itziar: unit of the quantity 'amount of substance' ... what do you think its meaning is? ... the meaning of the 'amount of substance'.

But... when you refer to amount of substance you seem to refer to mass of substance ... to so many grams... to so much mass of substance...to me it refers to quantity, to so many grams of substance.

[Example 2 (Esther, teaching in high school)]

01 Esther:

02

03

04

05

06

07

08

09

10 Interviewer:

11 Esther:

12
The 'mole' as amount of substance I compare it to a spoonful of flour as used to make a cake, so that they can also have a more concrete vision of what a 'mole' is ... that is, when I establish, for instance, a very simple reaction such as the obtaining of hydrochloric, ... here we make it equal because we must have an amount of mass on one side and the same on the other, ... then a 'mole' of chlorine is as if we need one spoonful of chlorine and this spoonful of chlorine needs another spoonful of...to get ... and there I introduce the 'mole' as the amount of substance.

And what do they understand by amount?

I have not asked them, I took it for granted ... as something from a product, as a certain, ... as an amount of mass.

Here we see that the quantity 'amount of subtance' is identified with mass (lines 47 of example 1 and line 12 from example 2). To corroborate these results the answers of two teachers to the continuation of the question are given.

Question (follow up). What do you think of the non-appearance of this quantity in the textbooks of Chemistry at any educational level?

[Example 1 (Rafa, teaching in high school)]

01 I haven't seen it either... I think it is all right that it does not appear. I don't need it 'as a unit to

02 measure something'.

[Example 2 (Ana, teaching at university] 


$\begin{array}{ll}01 & \text { Ana: } \\ 02 & \\ 03 & \\ 04 & \\ 05 & \text { Interviewer: } \\ 06 & \\ 07 & \\ 08 & \\ 09 & \\ 10 \\ 11 \\ 12 \\ 13 \\ 14 \\ 15 \\ 16 \\ 17\end{array}$

Amount of substance I interpret it as ...just as you say (in the definition of the previous question) ... one chooses the amount of substance equivalent to its molecular weight expressed in grams ... the amount of matter, isn't it? I'm asking you, you see.

For instance, with other quantities there is not so much doubt... for example, if one wants to find what the quantity whose unit is the kilogram is, the answer is: it's the mass. But, what is the quantity whose unit is the mole?... because the 'mole' is a unit. According to the IUPAC it is the unit of that quantity 'amount of substance'.

\begin{abstract}
But all in all it would be the molecular weight in grams, wouldn't it?. The 'mole' is a particular amount of substance, isn't it?... well, just like the kilogram, in fact. When you are measuring something with a relation. There you take it as a unit of the weight of the atom of carbon...the gram-molecule of carbon, don't you?... you say that has a value of twelve grams and that is what you take as a reference, isn't it?
\end{abstract}

In example 1 the introduction of the quantity 'amount of substance' is avoided 'because it is not needed' and in example 2 'amount of substance' is made identical to amount of matter (mass) (lines 3 and 4) and the 'mole' is defined just as Ostwald did (line 11).

\section{Non-problematic and non-historical visions of the introduction of the 'mole' and 'amount of subtance' concepts}

In table 4 the results concerning the introduction of the 'mole' concept in the sample of textbooks formerly described (study 4) are shown. In this table only $31 \%$ of the textbooks analysed made some reference to the type of general problem that the introduction of the 'mole' concept tries to solve. There were hardly any historical comments on aspects concerning the origin and evolution of the 'mole' concept, which reveals a non-historical and non-problematic vision of science when introducing this concept.

Table 5 shows the results of study 5: a survey inquiring about what would be a good method of introducing the 'mole' concept. The results obtained are consistent with those of the analysis of text and show that few teachers refer to the need to inquire into the problem the 'mole' concept tries to solve. There are very few

\section{Table 4. Introduction of 'mole' concept in textbooks reveals non- problematic and non-historical visions of scientific constructions}

\begin{tabular}{|c|c|c|c|c|}
\hline \multirow[b]{2}{*}{ Item } & \multirow[b]{2}{*}{ Propositional content } & \multicolumn{3}{|c|}{ Percentage } \\
\hline & & $\begin{array}{l}1976-1985 \\
(\mathrm{~N}=41)\end{array}$ & $\begin{array}{l}1986-1996 \\
(\mathrm{~N}=46)\end{array}$ & $\begin{array}{l}1976-1996 \\
\text { Total } \\
(\mathrm{N}=87)\end{array}$ \\
\hline 1 & $\begin{array}{l}\text { The general problem that the 'mole' } \\
\text { concept tries to solve is made explicit. }\end{array}$ & 12.2 & 47.8 & 31.0 \\
\hline 2 & $\begin{array}{l}\text { There are historical comments on the } \\
\text { original definition and/or the } \\
\text { evolution of the 'mole' concept. }\end{array}$ & 2.4 & 0.0 & 1.1 \\
\hline
\end{tabular}




\section{Table 5. Epistemological and didactic deficiencies on introduction of 'mole' concept (percentage $(N=47)$.}

Propositional content

Percentage

It is not pointed out what the problem attempted to be solved by the 88.2 introduction of the 'mole' concept is or the problem accounting for the need or use of its introduction.

No historical comment is made.

No qualitative approach to the concept is made before its introduction

It is not considered that the construction of the 'amount of substance' concept is made easier if related initially to the mass and relative mass of the elementary entity.

It is not considered that the construction of the 'amount of substance' concept is made easier if related initially to the number of elementary entities.

references to qualitative approaches to the concept before its operative definition. There is a very low percentage of teachers in the survey that consider it necessary to establish relations between mass or number of elementary entities and 'amount of substance' in order to make the counting of particles easier. No references to the history of chemistry were found either.

The results obtained in study 5 , in which we inquired about the aspects to consider when introducing the 'mole' concept in the classroom, are now presented. Here are some examples of the answers received:

What aspects do you consider would be convenient for the teacher to have in mind when introducing the concept (of mole) in the classroom?

1. Example of conventional strategy on the introduction of concepts

01 First of all one must explain what a 'mole' is, well, that is what is done, isn't it?

02 The 'mole' of an atom, the atom-gram, the 'mole' of the molecule and then, after 03 explaining the 'mole' of an atom, the atom-gram, the 'mole' of the molecule, one 04 goes on to their combining in a particular reaction. [Itziar, teaching at 05 university]

2. Example of a strategy where the emphasis is put on the prerequisites necessary in order to understand the 'mole' concept

01 Well, they should know all the previous stuff, they should have a good basis of 02 formulation of simple inorganic compounds, they must understand very well 03 what the atom is, what the molecule is, the structure of matter, the simple 04 substances, the compound ones, mixtures. If this is clear, I think that talking 05 about a number of particles, talking about amount of substance, is simpler. Then

06 we should see all this as being clear. [Rafa, teaching in High School]

None of the answers obtained included other possible considerations, such as justifying the introduction of the 'mole' concept, the utility of that concept, taking a qualitative approach and motivational aspects. Most of those interviewees teaching at university consider that students already know the 'mole' concept, so they go directly on to its application through the convenient calculations. These results are consistent with those obtained in previous surveys. 
All of the teachers interviewed said they did not know the historical origin or the evolution of the 'mole' concept. Some of the answers received are as follows:

Question. Do you know something about the historical origin of the 'mole' concept or about its evolution? If so, comment on it.

[Example 1. (Isabel, teaching in High School)]

01 I don't know much about the historical origin.

[Example 2. (Elena, teaching at University)]

01 Well, really I don't. I didn't take the time to study it.

\section{Teachers' misconceptions on the 'mole' concept}

Table 6 shows the results of the analysis of textbooks concerning the meaning attributed to the 'mole' concept (study 6). It was found that in $72.4 \%$ of the texts analysed, the 'mole' concept is wrongly understood as chemical mass and/ or number of elementary entities. Presented here are some examples of the content from Spanish secondary school textbooks:

The 'mole' is used in chemistry as a fundamental unit of amount of matter . . 1 mol of $\mathrm{Na}$ atoms $=6.02 \times 10^{23}$ atoms; 1 'mole' of molecules of $\mathrm{NO}_{2}=6.02 \times 10^{23}$ molecules. (Físicay Química 3 de Enseñanza Secundaria 1995).

One 'mole' of molecules or of atoms is the amount of substance, expressed in grams, which contains $6.10^{23}$ molecules or atoms. This amount coincides with the molecular or atomic mass of the substance. (Física y Química 2 de Bachillerato 1987).

Item 1 (table 6) reveals that a high percentage of the textbooks in the decade 1976-1985 attribute the meaning of mass to the 'mole'. Included here are definitions like Ostwald's (1900) in which the 'mole' is considered as a unit of chemical mass. There has been a positive advance in the last decade, i.e. there has been a decrease in the percentage of textbooks that identify the 'mole' as a mass unit. Nevertheless, the total percentage of textbooks that have considered it to be a mass unit during the last 21 years is still quite high (around 50\%). Item 2 shows that during the period 1976-1996, 20\% of the definitions of the mole wrongly identify it with the number of elementary entities.

Table 7 shows the results obtained on asking the teachers about how the 'mole' concept should be defined (study 7). The results show a worrying situation with

Table 6. In the textbooks the 'mole' concept is introduced wrongly attributing to it meanings of chemical mass and/or of number of elementary entities.

\begin{tabular}{llccc}
\hline & & \multicolumn{3}{c}{ Percentage } \\
\cline { 3 - 5 } Item & \multicolumn{2}{c}{$\begin{array}{c}\text { Propositional content } \\
1976-1985 \\
(\mathrm{~N}=41)\end{array}$} & $\begin{array}{c}1986-1996 \\
(\mathrm{~N}=46)\end{array}$ & $\begin{array}{c}\text { 1976-1996 } \\
\text { Total } \\
(\mathrm{N}=87)\end{array}$ \\
\hline 1 & $\begin{array}{l}\text { The 'mole' concept is attributed the } \\
\text { meaning of mass. }\end{array}$ & 75.6 & 32.6 & 50.6 \\
\hline & $\begin{array}{l}\text { The 'mole' concept is attributed a } \\
\text { meaning of elementary entities. }\end{array}$ & 19.5 & 23.9 & 21.8 \\
\hline
\end{tabular}




\begin{tabular}{lr} 
Table 7. Teachers wrongly attribute the \\
meaning of mass or of number of elemen- \\
tary units to the 'mole' concept. $(\boldsymbol{N}=\mathbf{4 7})$ \\
\hline Propositional contents & Percentage \\
\hline Meaning of mass & 23.4 \\
Meaning of number of elementary entities & 66.0 \\
Meaning of unit of 'amount of substance' & 10.6 \\
\hline
\end{tabular}

regard to the meanings attributed to the 'mole' concept: only $10.6 \%$ identify it with the unit of the quantity 'amount of substance'. Below is an example of an answer for every category:

As a unit of chemical mass. [Ana, teacher in high school]

As Avogadro's number of atoms, molecules, ions, etc. [Fernando, teacher in high school]

As unit of 'amount of substance' [Marian, teacher in high school]

When comparing these results with those of the analysis of texts, it can be shown that in both samples the total proportion of wrong identification (as mass and as number of elementary entities) is clearly a majority $(72.4 \%$ in texts and $89.4 \%$ in surveys).

Finally, the results obtained from the interviews asking whether or not two very typical definitions of 'mole' were adequate for teaching to students (study 8) are presented. Here are some of the answers obtained:

You will be given below two definitions of the 'mole' concept, extracted from a current bibliography, so that you can assess and comment on them, to see if you consider them adequate to be taught to your students:

(1) One 'mole' is the mass numerically equal (in grams) to the relative molecular mass of a substance. (McGraw Hill Encyclopaedia of Science and Technology. Volume 11)

(2) We defined a 'mole' of an element as Avogadro's number of atoms. (General Chemistry with Qualitative Analysis)

* Answer that identifies it with mass $(m)$

[Example 1. Kepa, teacher at university]

01 For me, the second definition, at least in principle, is not adequate for an

02 introduction. The other seems more convenient.

* Answer that that identifies it with the number of elementary entities $(N)$

[Example 2. Isabel, teacher in high school]

01 I find it simpler to say that the 'mole' is the number of particles, equally adopted

02 for all, and that given that the particles maintain a different proportion of mass

03 from one another, then, the mass of a 'mole' also maintains that same proportion

04 from one substance to another and the 'mole' is the number of particles, whether

05 they be atoms, molecules, or...

* Answer that identifies it with ' $m$ ' and with ' $N$ '

[Example 3. José, teacher in high school]

01 Both of them are all right, like others that are given, for instance the definition

02 of the I.S. 
These results reveal the existence of wrong ideas concerning the 'mole' concept, which is identified with mass (example 1, lines 1 and 2) and/or with the number of elementary entities (line 1 in examples 2 and 3 ). These results agree with those of the analysis of textbooks and surveys.

\section{Conclusions and implications for teaching}

It is widely accepted in science education that teachers need a deep understanding of a concept if they are to teach it well. In this sense, we have seen how some incorrect transpositions of the 'mole' concept are made when incorporating the original equivalentist meaning attributed to it by Ostwald in the beginning of the 20 th century $(50.6 \%$ in textbooks and $23.4 \%$ in surveys to teachers), ignoring the change of meaning that took place with the consolidation of the atomic-molecular theory within modern chemistry. Moreover, chemistry teachers have a confused idea about the 'amount of substance' concept (table 1), some making it identical to mass $(38.9 \%)$ and/or to number of elementary entities $(44.4 \%)$. This situation is consistent with the introduction of the 'mole' concept made in most chemistry textbooks that wrongly attribute to it meanings of chemical mass $(50.6 \%$ in table 5$)$ and/or number of elementary entities $(21.8 \%$ in table 5$)$. This erroneous vision is also maintained by authors and in publications whose prestige is widely acknowledged. Furthermore, the way the 'mole' concept is introduced in the syllabuses of normal teaching reveals epistemological deficiencies that could be one of the main causes of the little meaningful learning achieved by the students.

The conclusions drawn from the analysis of results concerning the thoughts of teachers can be summarized in scheme 1 .

The results obtained in this study are important for the teaching of the quantity 'amount of substance' and of its unit the 'mole' as well as for the training of chemistry teachers. Good teaching of any subject firstly calls for teachers to have a high grade knowledge of the concepts and theories of the discipline s/he is to teach. As Gil et al. (1991) point out: 'Knowing the discipline implies, among other aspects, knowing the problems that originated the construction of the scientific knowledge and, particularly, knowing how these concepts have evolved and which have been the main hindrances encountered'. This study has revealed the existence of serious difficulties in the teaching of the 'amount of substance' and of the 'mole'. This is due to the lack of knowledge we teachers have of the social-historical contexts of these concepts and of the evolution of their meanings through the adoption of the atomic-molecular theory by modern chemistry. Most chemistry teachers in our study do not hold an updated meaning of the quantity 'amount of substance'. Instead, teachers use the 'number of moles' they derive from the operative definition of the mole. Teachers transmit incorrect conceptions of this idea of mole, wrongly attributing to it meanings of chemical mass and/or number of elementary entities. These erroneous visions teachers have are quite widespread and are not only transmitted in the teaching of chemistry, but also in prestigious journals whose aim is to divulge scientific ideas among adults, such as you can see in the following examples:

One mole is the mass numerically equal (in grams) to the relative molecular mass of a substance. It is the amount of substance that contains the same number of molecules as there are atoms in 0.012 kilograms of carbon-12. The mole is an individual unit of 
The 'amount of substance' is not taught as a new quantity because it is considered to be the mass of substance (the expression 'amount of substance' would be synonymous with 'amount of matter'). However they do consider 'the mol' and the 'number of moles' as new concepts that have to be taught (the latter replacing what is now known as 'amount of subtance').

The 'mole' and 'number of moles' concepts are introduced in an arbitrary way, without any need to justify them:

a. In the case of an equivalent theoretical frame the 'mole' would be given the meaning Ostwald gave it, as equivalent or combination weight (mass) (although in a strict sense Ostwald always used the term 'amount of substance' in its meaning of mass) and, the number of moles would then be the amount of equivalent weights.

b. In the case of the atomistic theoretical frame, the 'amount of substance' is such that it solves the problem of counting macroscopically imaginable elementary units, and the 'mole' would be the unit of 'amount of substance'.

In brief, these concepts are taught without a clear contextualized theoretical setting (neither regarding their origins nor evolution).

This lack of contextual framing of the 'amount of substance' and 'mole' concepts leads to some misunderstandings of their meaning. The 'mole' is considered to be either a mass $(m)$ that has a given number of elementary entities or a given number of elementary entities $(N)$ that has a mass.

It is not known that the 'mole' is the unit of the macroscopic quantity 'amount of substance' $(n)$, a quantity that is different from the mass $(m)$ and from the number of elementary units $(N)$.

The conceptual errors concerning the meaning of the 'mole' are transferred to the operative definitions of 'number of moles' that are usually taught as: $n=m / M$ and $n=N / N_{A}$.

\section{Scheme 1. Teachers' thoughts about the concepts amount of substance and 'mole', as well as their teaching.}

mass, that is, it relates only to a given substance. If the relative molecular mass is $\mu$, 1 mole $=\mu$ grams, and the molar mass (M) of one mole is $\mu \mathrm{g} / \mathrm{mol}$. (McGraw Hill Encyclopedia of Science and Technology, 1987)

(...) For example, since the molecular weight of oxygen is 31.9988 , one mole of oxygen equals 31.9988 grams.

(...) Because this mass is not directly measurable, other ways of determining molecular weight are required, and a scale of relative values has been built around the concept of a mole (i.e., the amount of a substance in grams that corresponds to the sum of the atomic weights of all the atoms that make up the molecule; (..).

(...) The quantities $-\mathrm{H}$, or one gram of hydrogen atoms; $\mathrm{H}_{2}$, or two grams of hydrogen molecules; $\mathrm{H}_{2} \mathrm{O}$, or 18 grams of water molecules; Fe, or 56 (approximately) grams of iron atoms; $\mathrm{S}$, or 32 grams of sulphur atoms- are called moles of these substances. (The New Encyclopedia Brittanica, 1990)

Another important issue raised by our study concerns the training of teachers. A course on science education must include meaningful discussion about the scientific concepts. These are frequently introduced in an operative way, using formulas with almost no chemical meaning at all. We need alternative teaching that introduces these new concepts taking qualitative ideas as a first treatment. Once the concept has been approached qualitatively it would be possible to reach an operative definition. The strategies of teacher training must favour explicit, collective and constructive reflection by the teachers in order to help them solve the major comprehension problems their chemistry students have with these concepts. These 
strategies would have the treatment of science teaching-learning problems as an explicit aim, and teachers would be able to use their ideas in a functional way so as to deepen their understanding of their pupils' difficulties. This study has seen the problems chemistry teachers have with the meaning of the quantity 'amount of substance', so it is not surprising that students have not learnt the 'mole' concept in a meaningful way even though they do use it in an operative form. This points to another didactic problem concerning the poor teaching of these concepts and the need to use strategies more coherent with recent advances in the science education and, more particularly, with the constructivist view of learning.

The analysis of textbooks, the survey and the interviews with teachers show major problems in chemistry in high schools and universities at least in Spain. We think chemistry faculties should encourage research on this subject because of its importance for the training of teachers.

\section{References}

Azcona, R. (1997) Análisis crítico de la enseñanza-aprendizaje de los conceptos de 'cantidad de sustancia' y de mol. Una alternativa didáctica basada en el aprendizaje por investigación, Doctoral Thesis, San Sebastián: Universidad del País Vasco.

De Jong, O. (1994) Protocol analysis as a fruitful method of research in science education, Second European Summer School for Research in Science Education, Thessaloniki, Greece.

De Jong, O. (1996) La investigación activa como herramienta para mejorar la enseñanza de la Química: nuevos enfoques. Enseñanza de las Ciencias, 14(3), 279-288.

Dierks, W. (1981) Teaching the mole. European Fournal of Science Education, 3, 145-148.

Doménech, A., Casasús, E and Doménech, M. T. (1993) The classical concept of mass: theoretical difficulties and students' definitions. International Fournal in Science Education, 15(2), 163-173.

Dori, Y. J and Hameiri, M (1998) The 'mole' Environment' studyware: applying multidimensional analysis to quantitative chemistry problems. International fournal of Science Education, 20(3), 317-333.

Furió, C and Guisasola, J (1998) Difficulties in learning the concept of electric field. Science Education, 82(4), 511-526.

Furió, C., Azcona, R., Guisasola, G. and Mujika, E. (1993) Concepciones de los estudiantes sobre una magnitud “olvidada” en la enseñanza de la Química: la cantidad de sustancia. Enseñanza de las Ciencias, 11(2), 107-114.

Gil, D., Carrascosa, J., Furió, C. and Martinez-Torregrosa, J. (1991) La enseñanza de las Ciencias en la Educación Secundaria (Barcelona: ICE-Horsori).

Guggenheim, E. A. (1961) The 'mole' and related quantities. Fournal of Chemical Education, $30,86-87$.

Guggenheim, E. A. (1986) Thermodynamics. An advanced treatment for chemists and physicists (Amsterdam: North Holland Physics Publishing).

Knight, D. M. (1968) Classical scientific papers. Chemistry (London: Mills \& Boon Limited).

Kunn, T. (1962) The structure of scientific revolutions (Chicago: University of Chicago Press).

Lazonby, J. N., Morris, J. E. and Waddington, D. J. (1982) The muddlesome mole. Education in Chemistry, 19(4), 109-111.

Mills, I. M., Cvitas, T., Homann, K., Kallay, N. and Kuchitsu, K. (1993) IUPAC, Quantities, units and symbols in physical chemistry (Oxford: Blackwell).

Nelson, P. G. (1991) The elusive mole. Education in Chemistry, 28(4), 103-104.

Ostwald, G. (1930) La Escuela de Química (Barcelona: Gustavo Gili).

Ostwald, W. (1900) Grundlinien der Anorganischen Chemie (Leipzig: W. Engelmann).

Ostwald, W. (1902) The principles of Inorganic chemistry (London: Macmillan and Co. Limited). 
Ostwald, W. (1904) Elements de Chemie Inorganique (Paris: Gauthier-Villars ImprimeurLibraire).

Ostwald, W. (1917) Química Inorgánica Fundamental y Descriptiva (Barcelona: Manuel Marín Editor).

Schмidt, H. J. (1990) Secondary school students' strategies in stoichiometry. International Fournal of Science Education, 12(4), 457-471.

Schmidt, H. J. (1994) Stoichiometry problem solving in high school chemistry. International Fournal of Science Education, 16(2), 191-200.

Staver, J. R. and Lumpe, A. T. (1993) A content analysis of the presentation of the 'mole' conception in chemistry textbooks. Fournal of Research in Science Teaching, 30(4), 321-337.

Stromdahl, H., Tulberg, A. and Lybeck, L. (1994) The qualitatively different conceptions of 1 mole. International Fournal of Science Education, 16(1), 17-26.

Thuillier, P. (1990) De Arquimedes a Einstein, Las caras de la invención cientifica. Volumen 2 (Madrid: Alianza Editorial).

Toulmin, S. (1972) Human understanding: The collective use and evolutions of concepts (Princeton: Princeton University Press).

Tullberg, A., Stromdahl, H. and Lybeck, L. (1994) Students' conceptions of 1 mole and educators' conceptions of how they teach 'the mole'. International Fournal of Science Education, 16(2), 145-156. 